\title{
Influence of Weld Thermal Cycle on Properties of Flash Butt Weld- ed Mn-Cr-Mo Dual Phase Steel
}

\author{
P. K. GHOSH, P. C. GUPTA, O. M. PAL, R. AVTAR, ${ }^{1)}$ B. K. JHA ${ }^{11}$ and V. SAGAR DWIVEDI')
}

Welding Research Laboratory, Department of Mechanical and Industrial Engineering, University of Roorkee, Roorkee-247667, India. $\quad$ 1) Steel Authority of India Ltd., RDCIS, Ranchi 834 002, India.

(Received on January 11, 1993; accepted in final form on April 15, 1993)

\begin{abstract}
Flash butt welding of $3.7 \mathrm{~mm}$ thick $\mathrm{Mn}-\mathrm{Cr}-\mathrm{Mo}$ dual phase steel was carried out at different final jaw distance (FJD), where besides normal machine cooling (NMC), various instantaneous post weld cooling such as forced air cooling (FAC) and water spray cooling (WAC) were used. The energy input during welding was kept practically constant. The aim of the investigation was limited to study the influence of variation in weld thermal cycle, resulting from the change in FJD and post weld cooling, on the properties of the weldment. It was observed that during NMC the variation in FJD influences the weld thermal cycle and properties, but the application of forced cooling reduces the influence of FJD on them. The increase of cooling rate was found to reduce the softening of $\mathrm{HAZ}$, in presence of reduction in tempering of martensite at a distance of about $6.0 \mathrm{~mm}$ from the weld centre. During slow cooling, especially under NMC, the variation in FJD was found to reduce relatively the elongation of the weldment without affecting its UTS significantly where, the weldment was generally found to fail from $\mathrm{HAZ}, 6-7 \mathrm{~mm}$ away from weld centre. However, in case of fast cooling, especially under WSC, the variation in FJD was found to have an insignificant effect on the tensile properties of the weldment and the weldments were generally observed to be fractured from the base material.
\end{abstract}

KEY WORDS: dual phase steel; flash butt welding; weld thermal cycle; microstructure; hardness and tensile properties.

\section{Introduction}

In recent years the dual phase steel has gathered considerable attention of automobile industries for fabrication of various automotive components. ${ }^{1,4)}$ Out of these components the car wheel rim is one which requires flash butt welding during its fabrication. However, similar to other types of dual phase steels ${ }^{1,2\}}$ the flash butt welding of $\mathrm{Mn}-\mathrm{Cr}-\mathrm{Mo}$ dual phase steel has also faced considerable difficulties due to formation of a comparatively softer region in heat affected zone (HAZ) of the weld. ${ }^{3,5,6)}$ This behaviour weakens the weldment of dual phase steel by providing an early necking in this region under tensile loading. ${ }^{1-3,5-7)}$ The earlier investigations $s^{1,5-9)}$ reveal that this softening of certain region of $\mathrm{HAZ}$ essentially results from tempering of martensite, where the temperature during welding lies in the range of $600-650^{\circ} \mathrm{C}^{1,8)}$ However, in an earlier investigation $^{8)}$ it is also observed that a suitable control of weld thermal cycle, especially in case of instant post weld cooling under water spray, may reduce the extent of tempering of martensite in HAZ. Thus, it may save the weldment from the softening of $\mathrm{HAZ}$ significantly. ${ }^{10}$ ) Keeping in view this observation an investigation was carried out to study the influence of some flash butt welding parameters affecting the weld thermal cycle on the microstructure, hardness distribution and tensile properties of $\mathrm{Mn}-\mathrm{Cr}-\mathrm{Mo}$ dual phase steel weldment.

\section{Experimental Procedure}

\subsection{Welding}

Hot rolled dual phase steel plates of thickness $3.7 \mathrm{~mm}$ having chemical composition as shown in Table 1 were welded by flash butt welding process, where the contact area of the joint was kept as $3.7 \times 106 \mathrm{~mm}^{2}$. The plate surface was cleaned mechanically before welding. The schematic diagram of the welding process has been shown in Fig. 1. During welding the plates were gripped by the jaws having self cooling arrangement with the help of chilled water circulation through them. Out of two grips one was fixed and the other moved during welding (with an acceleration) from its initial position upto a certain distance called as "Welding Way". At the end of welding process the remaining gap between the grips was designated as final jaw distance (FJD). Within the weld-

Table 1. Chemical composition of base material. (wt $\%$ )

\begin{tabular}{ccccccc}
\hline $\mathrm{C}$ & $\mathrm{Mn}$ & $\mathrm{Si}$ & $\mathrm{Cr}$ & $\mathrm{Mo}$ & $\mathrm{S}$ & $\mathrm{P}$ \\
\hline 0.09 & 1.3 & 1.1 & 0.45 & 0.32 & 0.019 & 0.025 \\
\hline
\end{tabular}


ing way, during movement of the grip upto a certain distance (current way) the current passed through the plates and the grip traversed rest of the welding way without current. Within current way the grip moved upto a certain distance (flashing way) when the material flashed out as sparks from the contact surface of the plates. The welding process experienced an upsetting operation during movement of the grip from the end of flashing way upto rest of the welding way.

During welding the voltage was kept at $6.0 \mathrm{~V}$. In order to vary the weld thermal cycle the FJD was varied to 20,30 and $40 \mathrm{~mm}$ where, the current way, flashing way and welding way were kept constant. Moreover during welding at each FJD, besides the normal machine cooling attempts were also made to force cool the weld joint. The force cooling of weldment was carried out in the machine itself with the help of compressed air ( 4.5 bar) and water spray, applied immediately after the peak temperature is reached, marked in the $\mathrm{X}-\mathrm{Y}$ recorder
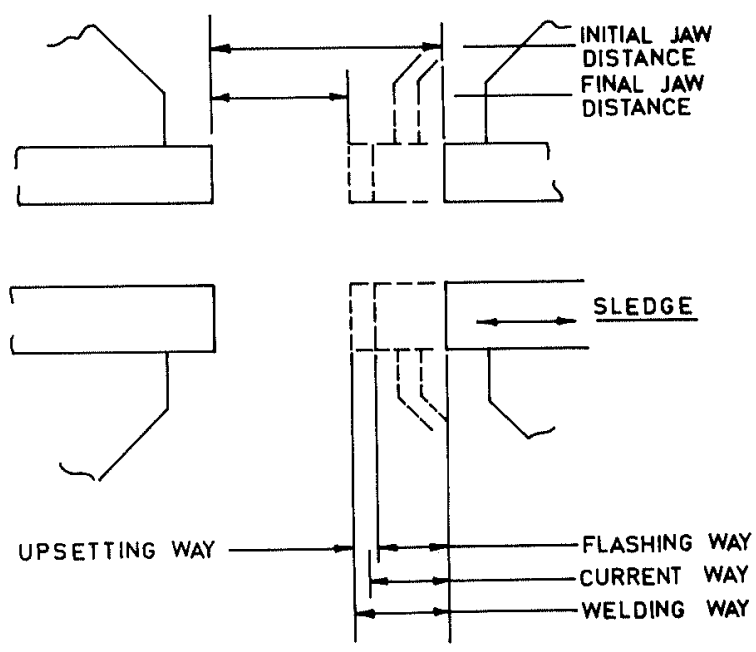

Fig. 1. Schematic diagram of the flash butt welding process.

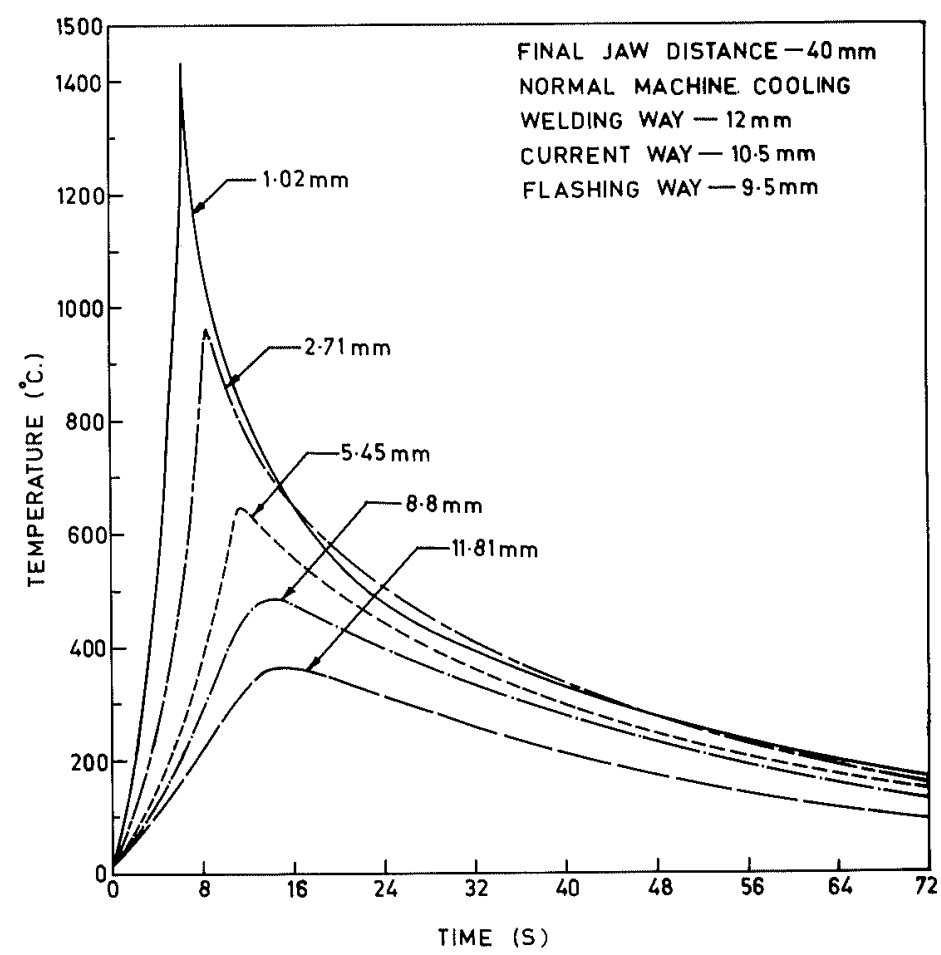

connected to the thermocouple placed in the region close to the weld centre.

\subsection{Weld Thermal Cycle}

The weld thermal cycle at different distance from the weld centre was obtained by suitable placing of $\mathrm{Pt}-\mathrm{Pt} / \mathrm{Rd}$ $(0.5 \mathrm{~mm}$ diameter) thermocouple on the plate surface as schematically shown in Fig. 2. The exact distance of thermocouple from the weld centre was determined under optical microscope by viewing the welded specimen prepared metallographically.

\subsection{Metallography and Microhardness}

The longitudinal sections of welded joints and base metal were prepared by standard metallographic procedure and etched in $2 \%$ nital solution. The influence of various welding conditions on the microstructure of weldment was studied under optical and scanning electron microscopes. The inclusion content of base material was estimated under optical microscope by following the standard point counting method. ${ }^{11)}$

For identification of various phases at base metal and $\mathrm{HAZ}$ of the weldment, the microhardness measurements were carried out at a load of $49.05 \times 10^{-3} \mathrm{~N}$. The hardness of base metal and that across the weld were

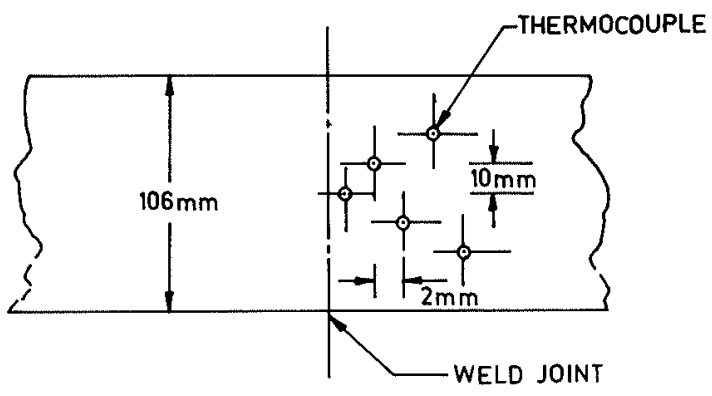

Fig. 2. Schematic diagram of the placing of thermocouples.
Fig. 3.

At a given FJD of $40 \mathrm{~mm}$ the typical weld thermal cycle observed under NMC. 
also studied by microhardness indentation at a comparatively higher load of $981.0 \times 10^{-3} \mathrm{~N}$ to average out the local hetrogeneities of matrix morphology upto a certain extent.

\subsection{Tensile Test}

The tensile tests of base material and the weldments were carried out by using flat tensile specimens (DIN 50 120) having cross-sectional area of the order of $74 \pm 2 \mathrm{~mm}^{2}$. In case of welded specimens the joint was kept at the centre of the specimen. The tests were performed at a cross head speed of $1 \mathrm{~mm} / \mathrm{min}$ and the elongation after fracture was estimated at a gauge length

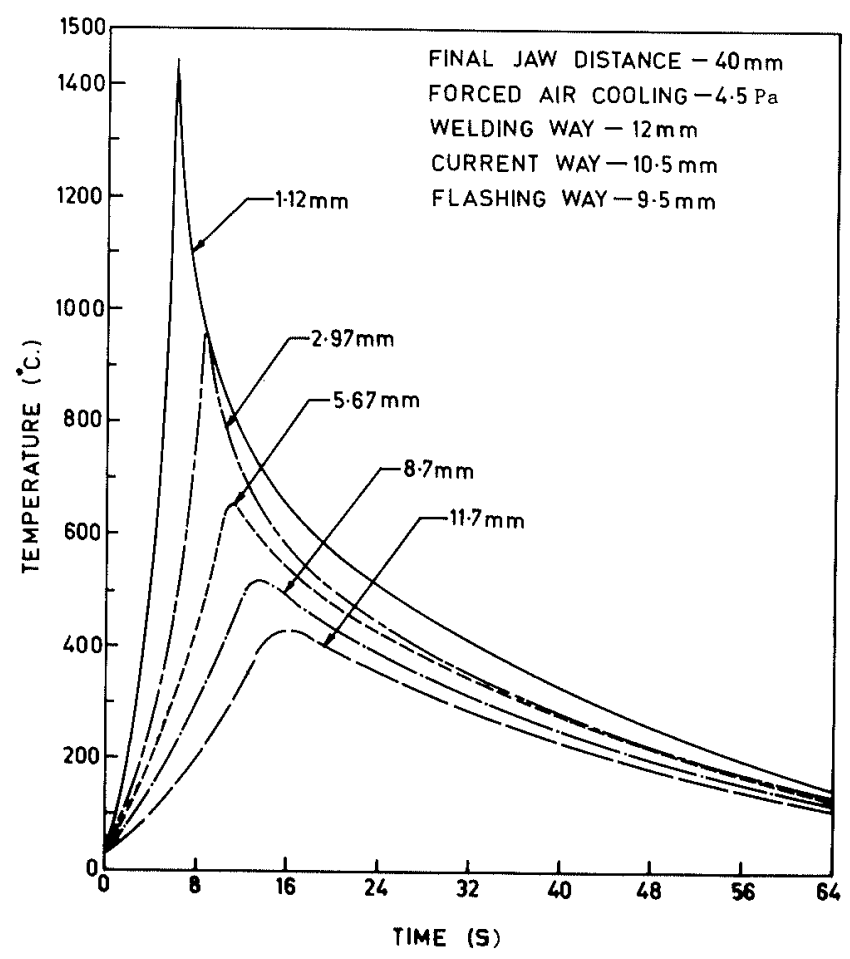

Fig. 4. At a given FJD of $40 \mathrm{~mm}$ the typical weld thermal cycle observed under FAC.

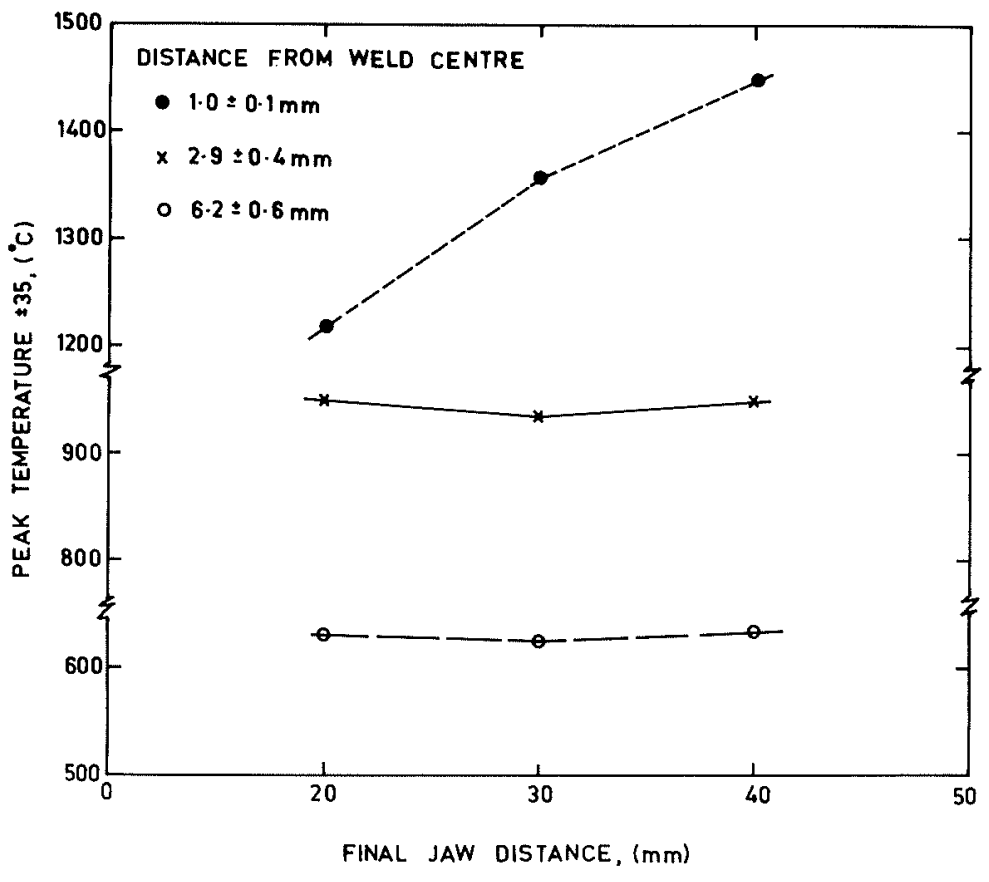

of $40 \mathrm{~mm}$.

\section{Results and Discussion}

\subsection{Weld Thermal Cycle and Microstructure}

The weld thermal cycle, affecting the behaviour of phase transformation at HAZ, governs the microstructure and properties of flash butt weldment of any material. The characteristics of phase transformation in $\mathrm{HAZ}$ is largely dependent on its peak temperature and cooling cycle. During flash butt welding the weld thermal cycle is primarily governed by the energy input (assumed to be practically constant in this work), simultaneous

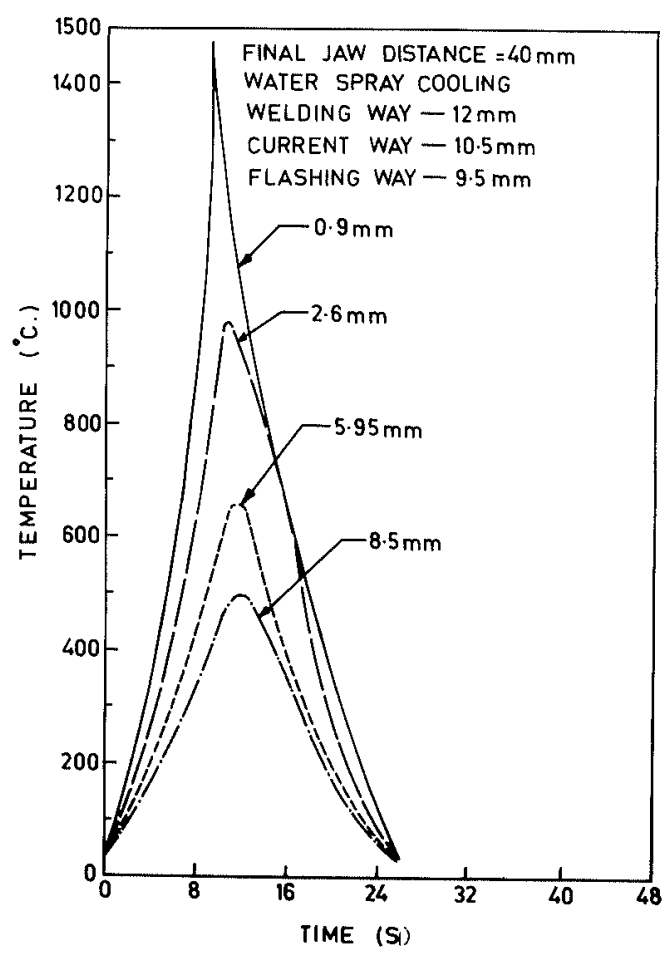

Fig. 5. At a given FJD of $40 \mathrm{~mm}$ the typical weld thermal cycle under WSC.
Fig. 6.

Influence of FJD on the peak temperature of HAZ at different distances from weld centre. 
cooling provided by the gripping jaws and the radiation loss as well as heat distribution within the material available in between the gripps.

Under various types of post weld cooling, such as the normal machine cooling (NMC), forced air cooling (FAC) and water spray cooling (WSC), the typical behaviour of weld thermal cycle observed at different distances from the weld centre are shown in Figs. 3, 4 and 5 respectively where, the FJD, welding way, current way and flashing way are kept constant as $40,12,10.5$ and $9.5 \mathrm{~mm}$ respectively. The influence of FJD on the peak temperature of different regions of HAZ with respect to weld centre are shown in Fig. 6. The figure shows that at a distance of about $1.0 \mathrm{~mm}$ away from weld centre the peak temperature enhances from about 1215 to 1355 and $1450^{\circ} \mathrm{C}$ with the increase in FJD from 20 to 30 and $40 \mathrm{~mm}$ respectively. As the location of this region is quite close to weld centre, this behaviour can be assumed as a trend for the influence of FJD on welding temperature. The peak temperature of HAZ has been found to be reduced with the increase in its distance from weld centre, being of the order of $930-950^{\circ} \mathrm{C}$ and $600-650^{\circ} \mathrm{C}$ at the distances of about 2.9 and $6.0 \mathrm{~mm}$ from weld centre respectively and in these regions the influence of FJD is marked to be comparatively insignificant. Thus, it depicts that during the use of final jaw distances mentioned above the HAZ within $3.0 \mathrm{~mm}$ and at about $6.0 \mathrm{~mm}$ from weld centre have reached the temperature regions for austenitic transformation and tempering martensite of base material, ${ }^{8)}$ respectively.

The role of variation in FJD, under different conditions of cooling such a NMC, FAC and WSC, on the cooling characteristics of different regions of $\mathrm{HAZ}$ has been shown in Table 2. The cooling times of HAZ within $3.0 \mathrm{~mm}$ and at $6.0 \mathrm{~mm}$ from weld centre are estimated in the temperature ranges of $800-500^{\circ} \mathrm{C}$, denoted as $t_{8-5}$ and $p-300^{\circ} \mathrm{C}$, denoted as $t_{p-3}$, respectively where, $p=620 \pm 20^{\circ} \mathrm{C}$. During welding the subsequent use of external cooling agents has been found to enhance the cooling rate of $\mathrm{HAZ}$, being maximum at WSC. In case of NMC and forced cooling scarcely upto FAC, the cooling rate of HAZ is found to be influenced by the FJD. It is observed that the cooling rate of HAZ, especially in the region comparatively closer to weld centre, decreases with the increase in FJD from 20 to

Table 2. The cooling rates of different regions of HAZ under various welding parameters.

\begin{tabular}{ccccc}
\hline \multirow{2}{*}{$\begin{array}{c}\text { Mode } \\
\text { of } \\
\text { cooling }\end{array}$} & $\begin{array}{c}\text { Distance from } \\
\text { weld centre } \\
(\mathrm{mm})\end{array}$ & \multicolumn{3}{c}{ Average cooling rate $\left({ }^{\circ} \mathrm{C} / \mathrm{sec}\right)$} \\
\cline { 3 - 5 } & & \multicolumn{3}{c}{ Final jaw distance $(\mathrm{mm})$} \\
& $1.0 \pm 0.1\left(t_{800-500}\right)$ & 40 & 19 & 24 \\
\multirow{3}{*}{ NMC } & $2.93 \pm 0.4\left(t_{800-500}\right)$ & 27 & 17 & 22 \\
& $6.2 \pm 0.6\left(t_{p-300}\right)$ & 15 & 10 & 11 \\
\hline \multirow{3}{*}{ FAC } & $1.0 \pm 0.1\left(t_{800-500}\right)$ & 43 & 27 & 33 \\
& $2.93 \pm 0.4\left(t_{800-500}\right)$ & 33 & 25 & 33 \\
& $6.2 \pm 0.6\left(t_{p-300}\right)$ & 16 & 14 & 14 \\
\hline \multirow{3}{*}{ WSC } & $1.0 \pm 0.1\left(t_{800-500}\right)$ & 71 & 73 & 71 \\
& $2.93 \pm 0.4\left(t_{800-500}\right)$ & 70 & 71 & 71 \\
& $6.2 \pm 0.6\left(t_{p-300}\right)$ & 70 & 70 & 70 \\
\hline
\end{tabular}
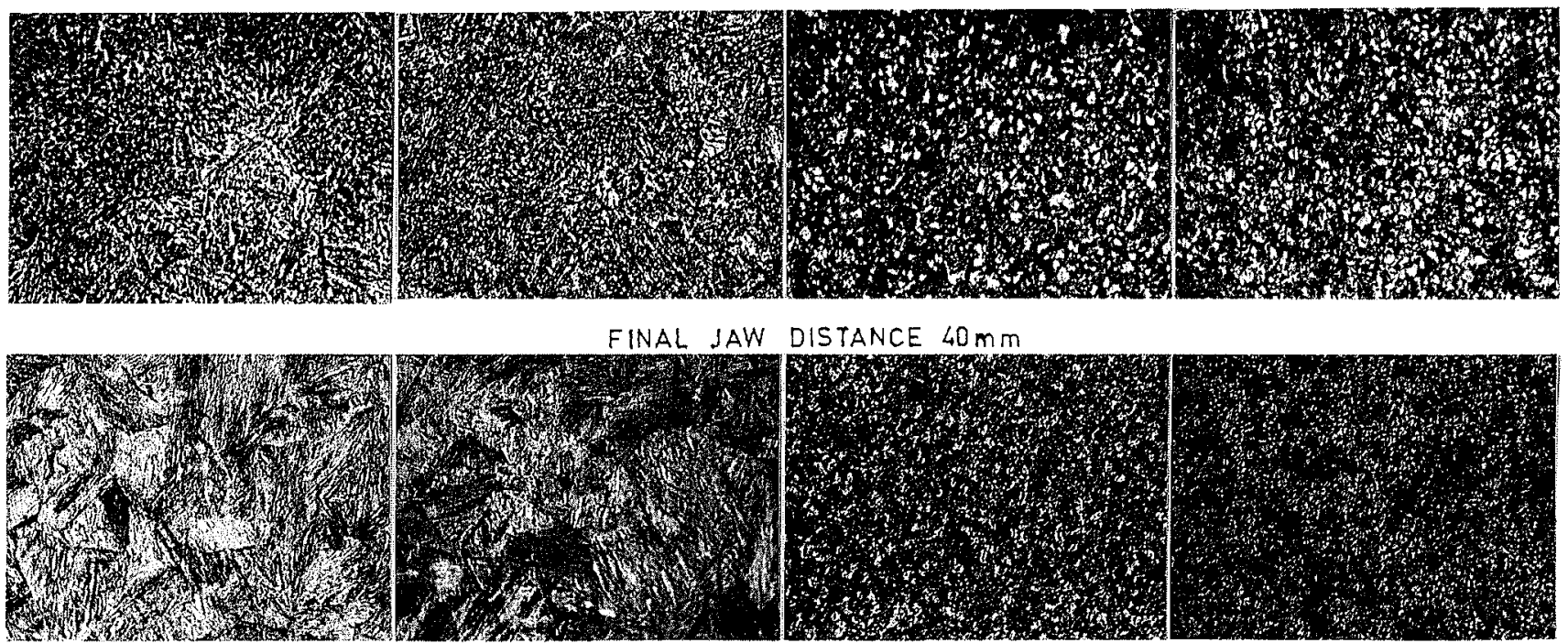

FINAL JAW DISTANCE $30 \mathrm{~mm}$
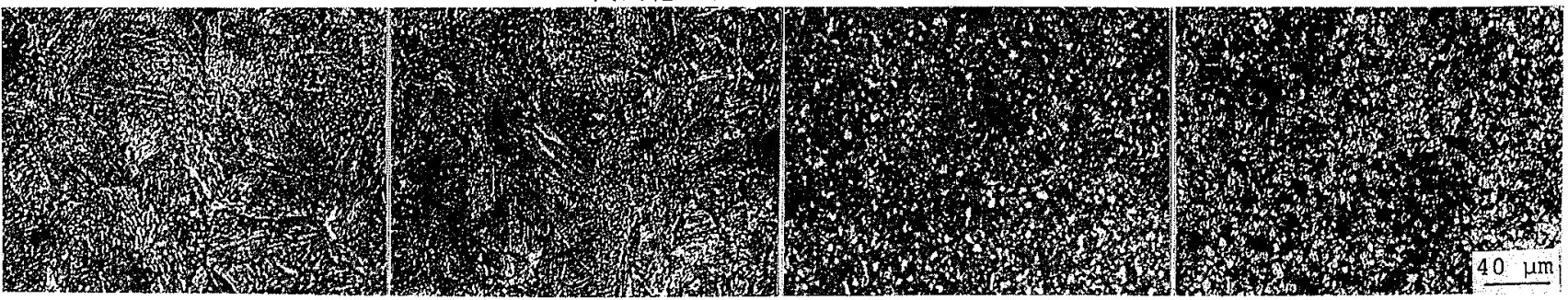

FINAL JAW DISTANCE $20 \mathrm{~mm}$

Fig. 7. During NMC at different FJD microstructures of weld centre and various regions of HAZ. 

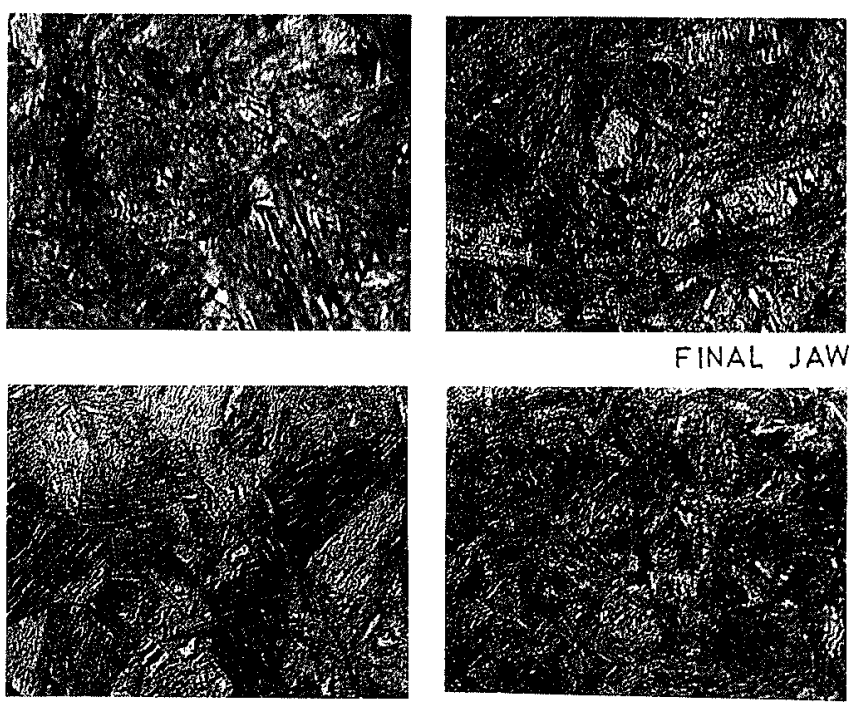

FINAL JAW

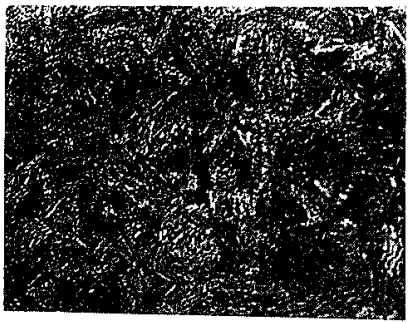

FINAL JAW DISTANCE $30 \mathrm{~mm}$
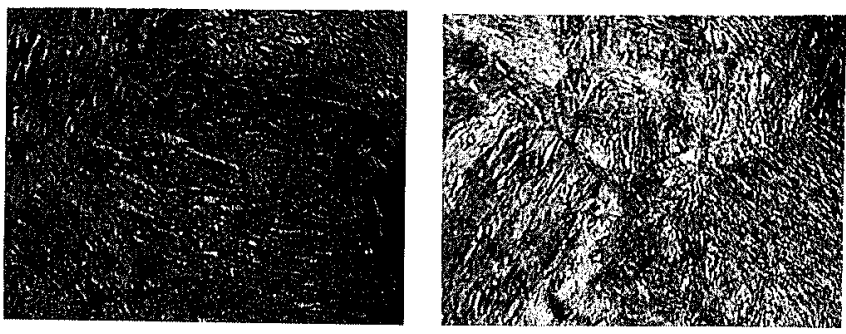

FINAL JAW DISTANCE $20 \mathrm{~mm}$

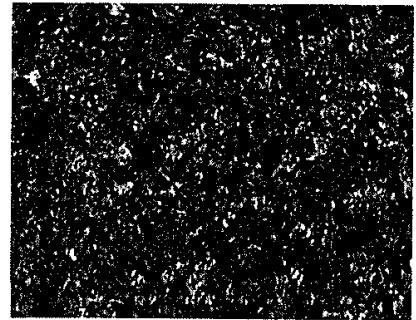

DISTANCE $40 \mathrm{~mm}$
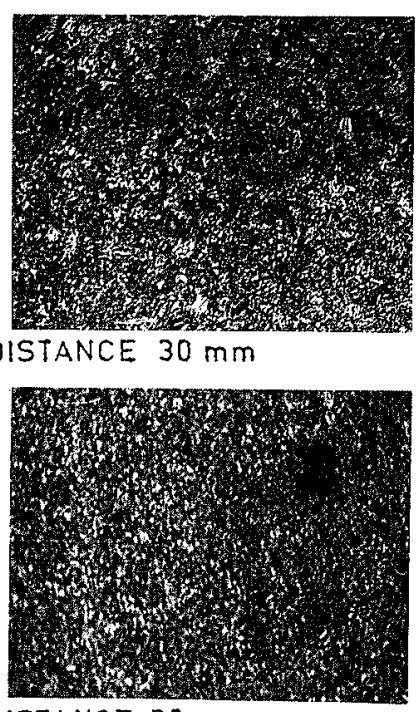

Fig. 8. During WSC at different FJD microstructures of weld centre and various regions of weld centre.

$30 \mathrm{~mm}$ followed by a moderate increase with a further increase in FJD to $40 \mathrm{~mm}$. The moderate increase in cooling rate inspite of the increase in FJD to $40 \mathrm{~mm}$ may have been primarily caused by the establishment of a different dimension of thermal balance, in presence of larger surface area and volume of material in between the jaws, from that observed in case of comparatively lower FJD. However, in case of WSC the cooling rate of any region of $\mathrm{HAZ}$ is found to be practically independent of FJD, possibly being predominantly controlled by the quenching effect. At a given FJD the increase in distance from weld centre is found to reduce the cooling rate of $\mathrm{HAZ}$, when the post weld cooling is kept other than the WSC.

The observations related to weld thermal cycle presented in Fig. 6 and Table 2 reveal that, the HAZ within $3.0 \mathrm{~mm}$ from weld centre may have bainitic/ martensitic transformation depending upon cooling rate where, the chances for martensitic transformation enhance especially under WSC. In case of NMC cooling rate of $\mathrm{HAZ}$ within $3.0 \mathrm{~mm}$ from weld centre has been found to decrease with the increase in FJD from 20 to $40 \mathrm{~mm}$. This may encourage more the bainitic transformation than the martensitic one. The peak temperature $\left(600-650^{\circ} \mathrm{C}\right)$ of $\mathrm{HAZ}$ at a distance of about $6.0 \mathrm{~mm}$ from weld centre, observed in Fig. 6, may cause tempering of martensite in this region. However, the extent of tempering of martensite shall depend upon $t_{p-3}$, controlling the retention of this region in tempering temperature range. Thus in case of WSC the short period $\left(t_{p-3}\right)$ of tempering of the order of about $4.0 \mathrm{sec}$, may

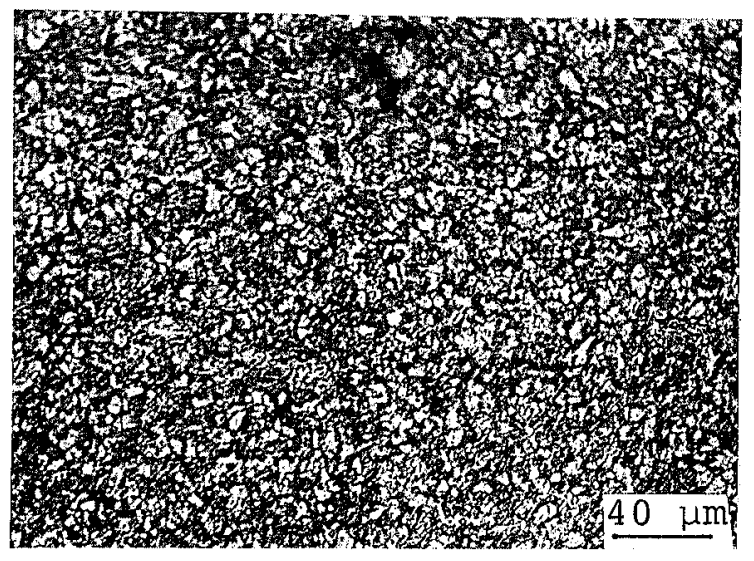

Fig. 9. Microstructure of base metal.

reduce the extent of tempering of martensite at $\mathrm{HAZ}$ $6.0 \mathrm{~mm}$ away from weld centre.

In agreement to above observations the influence of NMC and WSC on the microstructures of different regions of $\mathrm{HAZ}$, found at different FJD, are shown in Figs. 7 and 8 respectively. The tempering of martensite in HAZ, about $6.0 \mathrm{~mm}$ away from weld centre, has been marked as darkest colonies in the matrix (Fig. 7). As discussed earlier these colonies have been found to reduce significantly in the similar region of HAZ produced under WSC (Fig. 8) and the microstrctural features of the same look close to that of base material (Fig. 9). The tempering of martensite has also been identified by the microhardness $\left(49.05 \times 10^{-3} \mathrm{~N}\right)$ of these colonies as of the order of $310 \mathrm{VHN}$, which is comparatively lower 


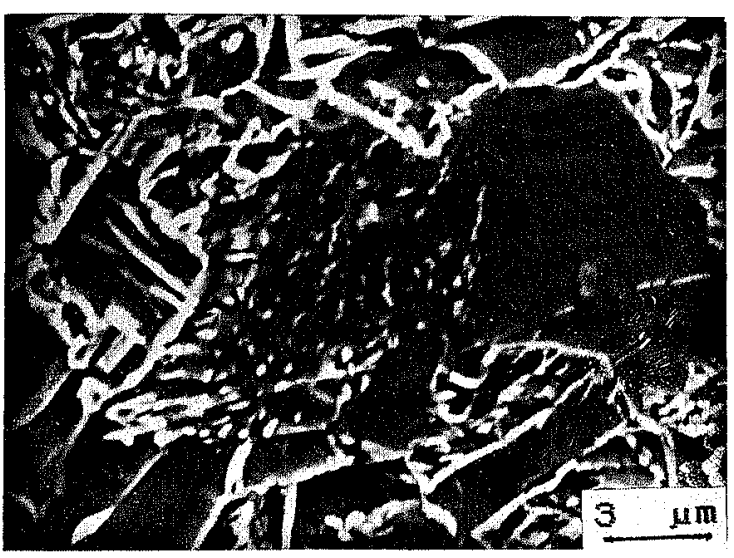

Fig. 10. Scanning electron micrograph showing the tempering of martensite at certain regions of $\mathrm{HAZ}$.

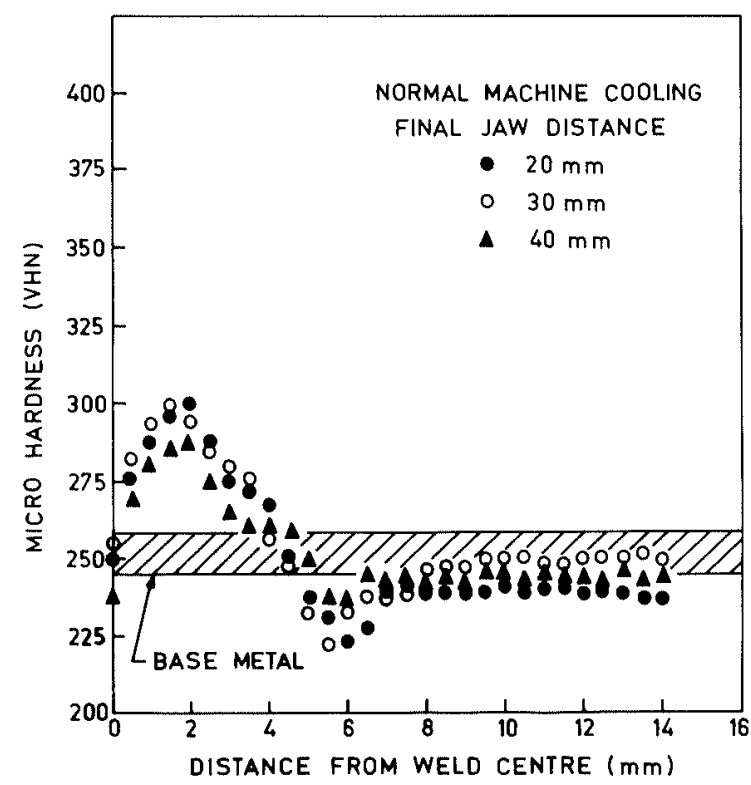

Fig. 11. During NMC the typical nature of variation in microhardness across the weld prepared at different FJD.

than that of relatively dark martensite colonies of base metal measured as about $430 \mathrm{VHN}$. The typical scanning electron micrograph presented in Fig. 10 also confirms the tempering of martensite, in similar region of $\mathrm{HAZ}$, revealed as breaking of needles in certain area.

\subsection{Microhardness of Weldment}

The influence of NMC, FAC and WSC on the variation in microhardness $\left(981.0 \times 10^{-3} \mathrm{~N}\right)$ behaviour across the weld, prepared at various FJD are shown in Figs. 11, 12 and 13 , respectively. The figures depict that under any condition of welding the weld centre becomes comparatively softer than its surrounding. This may be attributed to coarsening of microstructure, as revealed in Figs. 7 and 8 , as well as to the transformation of comparatively higher amount of ferrite ${ }^{8)}$ in this region. However, in this regard the possibility of decarbonisation ${ }^{5)}$ affecting the characteristics of bainite/martensite transformation in this region may not be ignored. The increase in cooling rate in order of FAC to WSC reduces the transformation of ferrite ${ }^{8)}$ and possibly the decarbonisation, along with

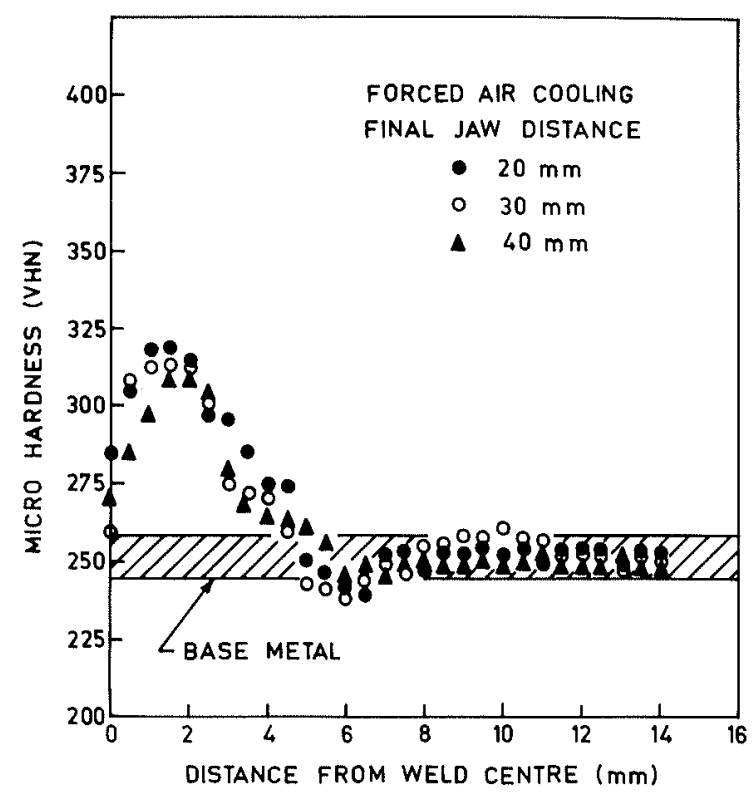

Fig. 12. During FAC the typical nature of variation in microhardness across the weld prepared at different FJD.

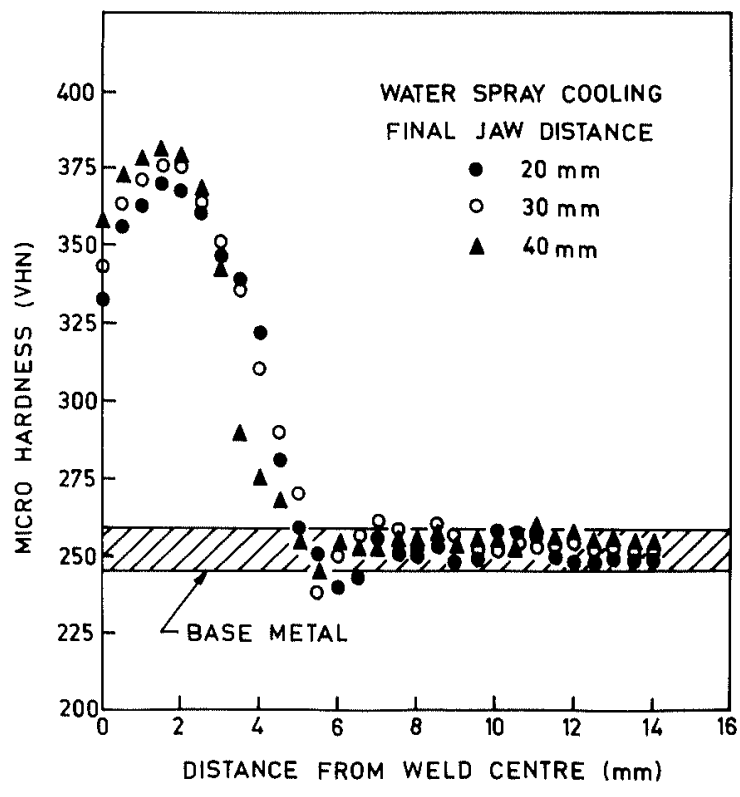

Fig. 13. During WSC the typical nature of variation in microhardness across the weld prepared at different FJD

enhancement in transformation of martensite in the central part of the weld. This may have enhanced the hardness of weld centre as shown in Figs. 12 and 13 in comparison to that observed (NMC) in Fig. 11. In general the maximum microhardness of the weldment observed in the region of about $2 \mathrm{~mm}$ away from weld centre may have been caused by the transformation of comparatively higher amount of bainite/martensite of relatively fine nature as typically shown in Fig. 7. However, the increase in cooling rate in order of FAC to WSC (Table 2), enhancing the bainite/martensite transformation around weld centre as typically shown (WSC) in Fig. 8, may have enhanced the hardness of central region of the weld and reduced comparatively the difference in hardness of weld centre from that of its surroundings (Figs. 12 and 


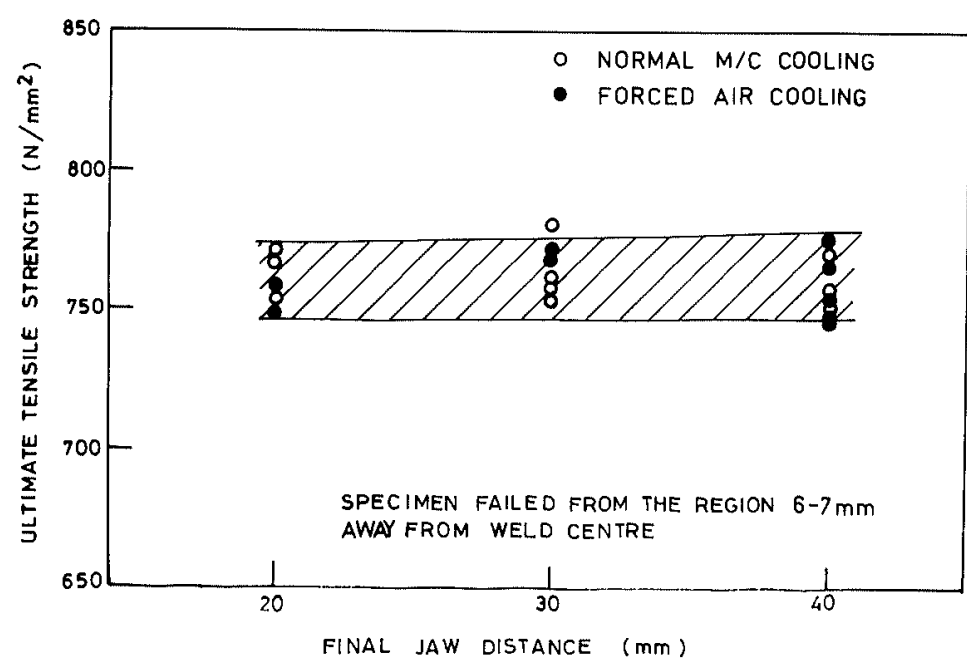

Fig. 14.

Variation of ultimate tensile strength with a change in FJD at different modes of cooling; fracture from the region 6-7 $\mathrm{mm}$ away from weld centre.
13). In agreement to the earlier discussions, showing the increase in bainite transformation with the increase in FJD, the peak hardness of HAZ seems to be reduced with the increase in FJD as revealed (Fig. 11) especially in case of NMC. But the opposite behaviour is observed (Fig. 13) in case of WSC possibly due to quenching from higher peak temperature at larger FJD as shown in Fig. 6.

The occurence of tempering of martensite in $\mathrm{HAZ}$ at $6.0 \mathrm{~mm}$ away from weld centre has been found to reduce the random microhardness of this region to a level below that of base material. This behaviour is especially observed in case of NMC (Fig. 11), where the cooling rate (Table 2) is comparatively low. But the use of forced cooling, by FAC and particularly by WSC, has checked the lowering of hardness of this region below that of base material as shown in Figs. 12 and 13, respectively, due to significant reduction in $t_{p-3}$.

\subsection{Tensile Properties of Weldment}

The tensile properties of base plate has been shown in Table 3. During tensile test of the weldment prepared under different conditions of cooling as well as FJD the specimens have been found to fracture either from HAZ or from base metal depending upon welding parameters. The tensile properties of the weldment are, therefore, analysed by dividing them into two groups such as, those which have failed from the region about 6-7 mm away from weld centre representing the failure from $\mathrm{HAZ}$ and the others which have failed from the region beyond $20 \mathrm{~mm}$ away from weld centre representing the failure from base metal.

Under different conditions of post weld cooling the influence of FJD on the ultimate tensile strength of the weldments fractured from the regions of about $6-7 \mathrm{~mm}$ away and those beyond $20 \mathrm{~mm}$ away from weld centre are shown in Figs. 14 and 15 respectively. The figures show that in case of NMC and FAC the weldments usually fail from the HAZ at a distance of about 6-7 mm away from weld centre (Fig. 14) and in case of WSC including few cases of FAC the weldments are found to fail from the region beyond $20 \mathrm{~mm}$ away from weld centre. In case of NMC and in most of the cases of FAC the failure of weldments from HAZ may be attributed
Table 3. Mechanical properties of base metal.

\begin{tabular}{ccc}
\hline $\begin{array}{c}\mathrm{UTS} \\
\left(\mathrm{N} / \mathrm{mm}^{2}\right)\end{array}$ & $\begin{array}{c}\text { YS } \\
\left(\mathrm{N} / \mathrm{mm}^{2}\right)\end{array}$ & $\begin{array}{c}\text { Elongation } \\
(\%)\end{array}$ \\
\hline 730 & 525 & 17.5 \\
\hline
\end{tabular}

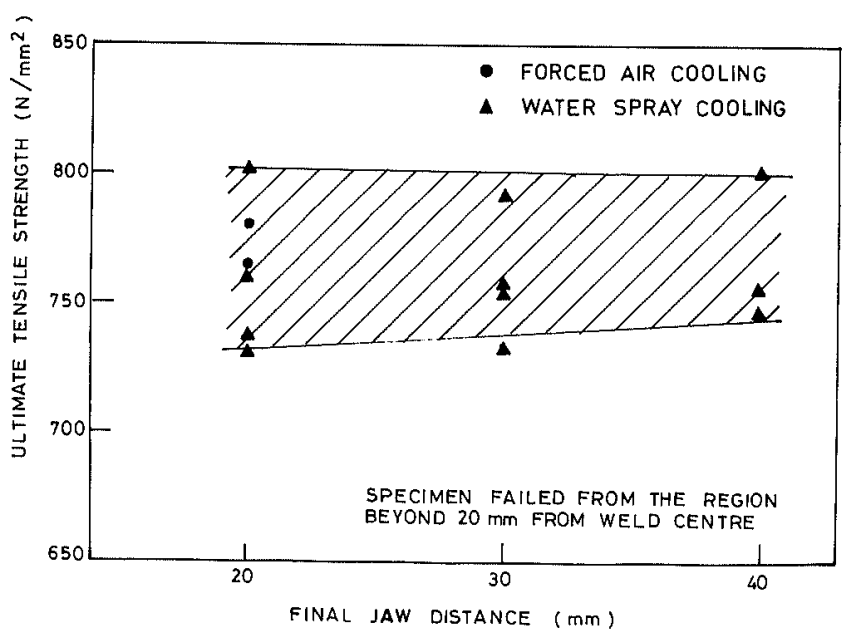

Fig. 15. Variation of ultimate tensile strength with a change in FJD at different modes of cooling; fracture from the region beyond $20 \mathrm{~mm}$ from weld centre.

to the occurence of tempered martensite. However, in case of WSC, the reduction in the extent of tempering of martensite at $\mathrm{HAZ}$, resulting in retention of its strength, may have pushed the fracture region away from the HAZ (Fig. 15). The range of ultimate tensile strength of the weldments fractured from HAZ (Fig. 14) is found comparatively narrower than that of the weldments fractured from base material (Fig. 15). The scattering observed in ultimate tensile strength of the weldments may have been primarily caused by the presence of inclusions, which are observed to be of the order of $8 \pm 1 \mathrm{vol} \%$ in base material. These inclusions have possibly played a comparatively more dominant role in case of fracture from base material than that in case of fracture from comparatively softer HAZ having better flow properties. The presence of inclusion in base material is clearly revealed in the scanning electron micrograph presented in Fig. 16. The results depicted in Figs. 14 and 


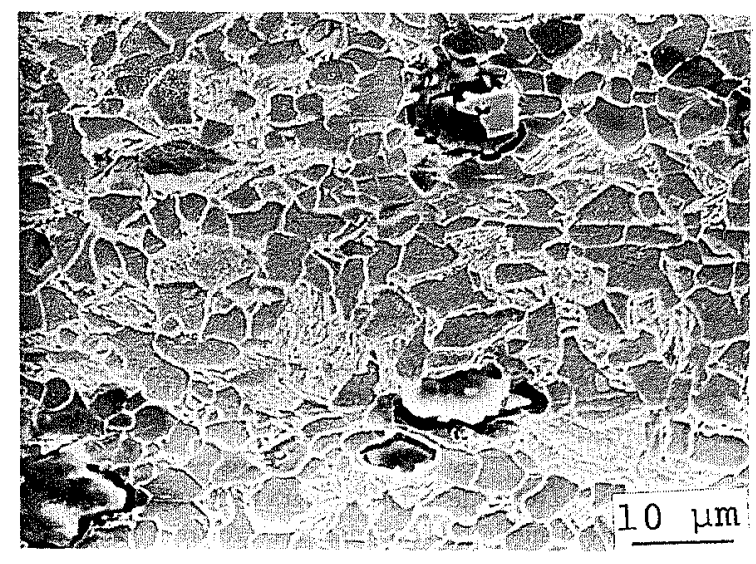

Fig. 16. Scanning electron micrograph showing the presence of inclusion in base material.

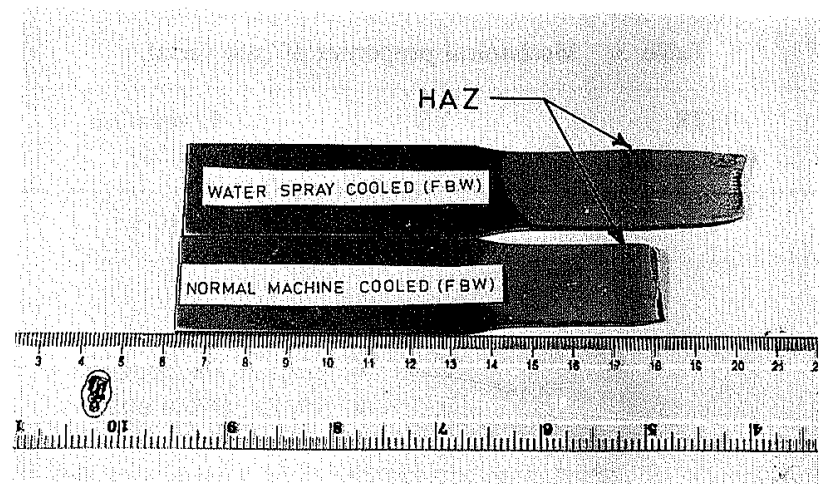

Fig. 17. Influence of post weld cooling on the shifting of fracture regions from weld centre under tensile test.

15 also show that variation in FJD does not have any significant influnce on the ultimate tensile strength of the weldment. In two extreme conditions of post weld cooling such as the NMC and WSC, the typical behaviour of failure of weldments from the HAZ (6-7 mm away from weld centre) and base material respectively are shown in Fig. 17.

Under different conditions of post weld cooling the influence of FJD on the elongation of weldments fractured from the regions of about $6-7 \mathrm{~mm}$ and beyond $20 \mathrm{~mm}$ away from weld centre is shown in Figs. 18 and 19, respectively. The Fig. 18 reveals that in case of weldments prepared under NMC and partly under FAC the increase in FJD from 20 to $40 \mathrm{~mm}$ has been found to reduce comparatively the elongation of the weldment from about 15.5 to $13.0 \%$ where, the fracture generally occurred in HAZ. However, Fig. 19 shows that in case of weldments prepared under WSC and a few under FAC when, they fracture from base material, the variation in FJD does not have any significant influence over elongation being of the order of about $16.5 \%$. The comparatively lower elongation observed in case of fractures from HAZ than those found in case of fractures from base material may be primarily attributed to the restriction of necking (Fig. 17) in former one due to presence of strong bainite/martensite region adjacent to the region of fracture. However, in Fig. 18 the observed decrease in elongation with the increase in FJD from 20 to $40 \mathrm{~mm}$, may have been caused by the enhanced tem-

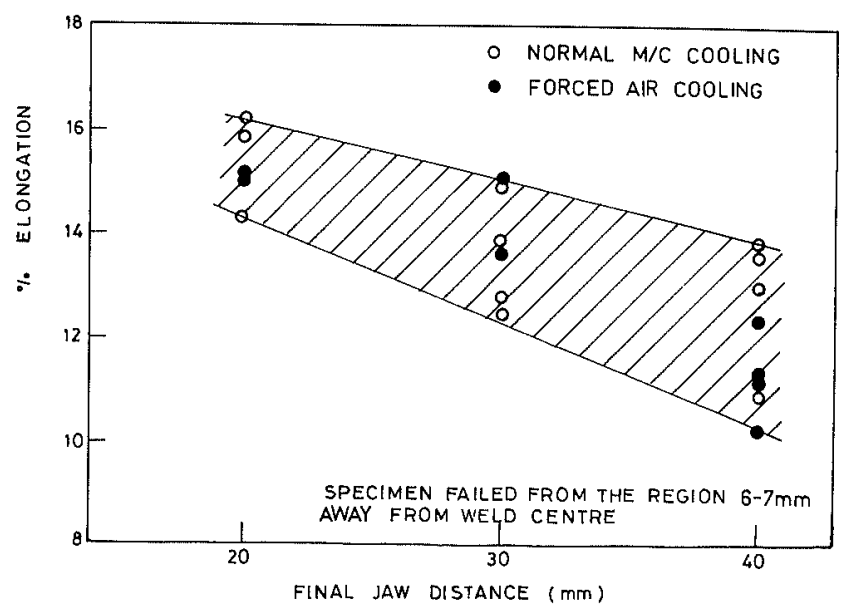

Fig. 18. Variation in elongation with a change in FJD at different modes of cooling; fracture from the region 6-7 mm from weld centre.

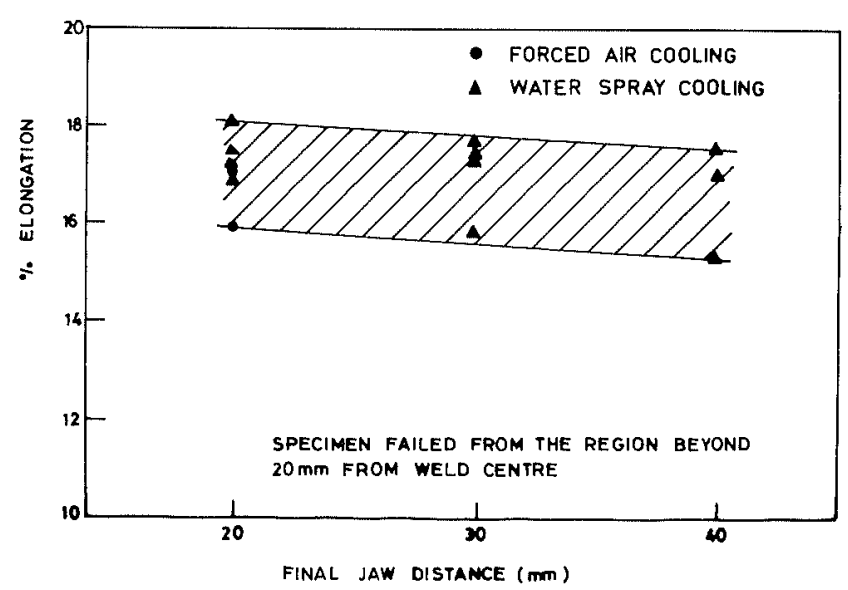

Fig. 19. Variation in elongation with a change in FJD at different modes of cooling; fracture from the region $20 \mathrm{~mm}$ from weld centre.

pering of martensite in the embrittlement temperature range of 250 to $450^{\circ} \mathrm{C}$ for this stee $1^{9)}$ as well as due to concentration of strain at the comparatively softer region of HAZ.

\section{Conclusion}

During NMC the variation in FJD influences to some extent the weld thermal cycle and weldment properties, but the increase in extent of froced cooling reduces the influence of FJD on the same. The use of forced cooling influences the weldment properties significantly. The increase in cooling rate in order of using the FAC and WSC reduces the tempering of martensite in $\mathrm{HAZ}$, about $6.0 \mathrm{~mm}$ away from weld centre, and thus restricts the reduction of hardness of this region. During comparatively slow cooling especially under NMC the variation in FJD does not influence the UTS significantly, but reduces relatively the elongation of the weldment where, the fracture occurs from HAZ 6-7 mm away from weld centre. However, during fast cooling, especially of the order of WSC, the variation in FJD does not have any significant influence on the tensile properties of the weldment, and the fracture occurs from its region of base 
material.

\section{REFERENCES}

1) K. Kunishige, N. Yamauchi, T. Taka and N. Nagao: Proc. Int. Conf., Detroit, Mich., (1983), Feb. 28-March 4, 5.

2) M. S. Rashid and G. D. Lawrence: SAE Trans., 87 (1978), 552.

3) B. K. Jha, Ram Avtar, V. S. Dwivedi and V. Ramaswamy: Proc. Int. Conf. on Welding Tech., University of Roorkee, Roorkee, U. P., India, (1988), Sept. 26-28, III-199.

4) B. Pollard: Weld. J. Research Suppl., (1974), Aug., 348

5) P. K. Ghosh, P. C. Gupta, Raw Avtar and B. K. Jha: Proc. Int.
Conf. on Welding Tech., University of Roorkee, Roorkee, U.P., India, (1988), Sept. 26-28, II-53.

6) B. K. Jha, N. S. Mishra and V. Ramaswamy: Steel India, 6 (1983), No. 2, 114.

7) M.S. Rashid and A. E. Rthke: SAE Tech. pap. 810026,(1981), 11

8) P. K. Ghosh: ISIJ Int., 30 (1990), 317.

9) B. K. Jha, V. S. Dwivedi and Ram Avtar: Steel Authority of India Ltd., RDCIS, Ranchi-834002, INDIA, unpublished report.

10) P. K. Ghosh and L. Dorn: Schweissen und Scniden, 43 (1991), 29

11) R. T. Dehoff and Rhines: Quantitative Microscopy, McGraw Hill, New York, (1968), 70. 